\title{
Numerical Study of Hydrogen Addition Fuel on Soot Formation in Axisymmetric Laminar Methane/Air Diffusion Flames
}

\author{
Bencheng Zhu ${ }^{1}$, Yuhan Zhu ${ }^{1}$, Jiajia $\mathrm{Wu}^{1}$, Kun $\mathrm{Lu}^{1}$, Yang Wang ${ }^{1}$, Yuyu Lin ${ }^{1}$, and Mingyan Gu${ }^{1, *}$ \\ ${ }^{1}$ School of Energy and Environment, Anhui University of Technology, Ma'anshan 243002, Anhui, China
}

\begin{abstract}
This article employs the CoFlame Code to investigate the effects of hydrogen addition to fuel on soot formation characteristics in laminar coflow methane/air diffusion flames at atmospheric pressure. Numerical calculations were carried out using a detailed $\mathrm{C}_{1}-\mathrm{C}_{2}$ gas phase reaction mechanism and a soot model consisting of two pyrene molecules colliding into a dimer as soot nucleation, hydrogen abstraction acetylene addition (HACA) and pyrene condensation as surface growth, and soot oxidation by $\mathrm{O}_{2}, \mathrm{O}$ and $\mathrm{OH}$ radicals. Calculations were conducted for five levels of hydrogen addition on volume basis. To quantify the chemical effect of hydrogen, additional calculations are performed for addition of inert pseudo-hydrogen $\left(\mathrm{FH}_{2}\right)$. The addition of $\mathrm{H}_{2}$ or $\mathrm{FH}_{2}$ does not have a strong influence on flame temperature. The results confirm that hydrogen addition can inhibit soot formation in the methane/air diffusion flame by reducing both the nucleation and surface growth steps of soot formation process. The effect of $\mathrm{FH}_{2}$ addition on soot formation suppression is more remarkable than $\mathrm{H}_{2}$, indicating that the chemical effect of hydrogen added to methane prompts soot formation. The dilution effect of hydrogen addition on soot formation suppression is stronger than its chemical effect on soot formation enhancement the present findings are consistent with those of previous numerical studies.
\end{abstract}

\section{Introduction}

For a long time, the emission of pollutants from combustion devices has attracted the public attention. In particular, carbon nanoparticles (soot) produced by incomplete combustion of hydrocarbon fuels are one of the main sources of $\mathrm{PM}_{2.5}$ in the atmosphere that causes severe harm to human health and the environment [1-2]. These challenges have spurred researchers to look for alternative fuels that can reduce soot emissions.

Park et al. [3] performed numerical simulations to study the effect of hydrogen on the formation and oxidation of soot produced by acetylene/air laminar premixed flames. The calculation results illustrate that hydrogen can reduce the oxidation rate of acetylene and reduce the formation of benzene on the surface of the burner. On the other hand, hydrogen also accelerates the formation of benzene above the main pyrolysis zone due to the increased rate of reversible reaction of hydrogen abstraction based on the HACA mechanism, and leads to a remarkable delay in the formation of larger polycyclic aromatic hydrocarbons that finally reduces the soot nucleation rate and consequently inhibits soot formation. Sun et al. [4] conducted experiments to study the effect of hydrogen and nitrogen on the volume fraction of soot in an ethylene/air laminar diffusion flame and found out that the dilution of fuel with hydrogen or nitrogen reduced the peak soot volume fraction and nitrogen is more effective than hydrogen. Guo et al. [5] carried out a numerical study on the effect of hydrogen on the growing process of soot in an ethylene/air diffusion flame. They discovered that the suppression effect by hydrogen on the growth of soot was caused by the changes in the concentration ratio of $[\mathrm{H}] /[\mathrm{H} 2]$ in the reaction zone. Migliorini et al. [6] carried out the study of the effects of hydrogen and helium addition to fuel on soot formation in laminar coflow methane/air diffusion flames. The experimental results suggest that both hydrogen and helium can inhibit soot formation, but helium is more effective than hydrogen. Liu et al. [7] adopted the revised ABF mechanism to predict the effects of hydrogen addition to methane on soot formation on the basis of the experiments performed by Migliorini [6]. The calculation results indicate that with hydrogen addition, the growth of soot is inhibited. In addition, the predicted soot volume fractions are an order of magnitude smaller than the experimental data. The above results show that hydrogen can inhibit soot formation to a certain extent, whereas the inhibitory mechanism of hydrogen on soot formation in hydrocarbon flames is still not fully understood.

\section{Numerical model}

The detailed description of gas phase governing equations of mass, momentum, energy and species components in the axisymmetric cylindrical coordinate system $(\mathrm{r}, \mathrm{z})$ can be found in the literature $[5,8,9]$ and are therefore not described here.It is worth noting that the gravity term in the axial direction in the momentumequation and the 
thermal radiation source term in the energy equation are retained.

The gas phase reaction mechanism used in this study is the $\mathrm{C}_{1}-\mathrm{C}_{2}$ chemistry model proposed by Chernov et al. [7], (hereinafter referred to as $\mathrm{C}_{1}-\mathrm{C}_{2}$ mechanism) consisting of 94 components and 733 reactions.Detailed soot models are described in literature [5].It is assumed that soot nucleation is due to collision of two pyrene molecules into a dimer, and the subsequent surface growth and oxidation follow the HACA mechanism [1011] with addition contribution to surface growth by pyrene condensation. It is noticed that only the thermal diffusion rates of the lightest components $\mathrm{H}$ and $\mathrm{H}_{2}$ are considered.

The governing equations are discretized by the finite volume method. The coupling of pressure and velocity is handled by the SIMPLE algorithm. The diffusion term and the convection term in the conservation equation are discretized by the central difference and the upwind difference scheme, respectively. In each control volume, the governing equations of gas phase composition, soot mass fraction and soot number density are solved in a fully coupled manner while the momentum, energy and pressure correction equations are solved with the threediagonal matrix algorithm. The discrete ordinate method is used to calculate the radiation source term in the energy equation [12] in which the absorption coefficient of the mixture is calculated by the statistical narrow-band correlation $\mathrm{k}$ method proposed by Liu and Smallwood [13-14].

The flame configuration is an axisymmetric coflow laminar diffusion flame generated by a Gülder burner. The fuel is delivered through a central tube with an inner diameter of $5.00 \mathrm{~mm}$ (with the thickness of $0.90 \mathrm{~mm}$ ). The oxidant (air) flows through an annular region between the fuel tube and a concentric tube with an inner radius of 45 $\mathrm{mm}$. The computational domain is an area of $10.6 \mathrm{~cm} \mathrm{(z)}$ $\times 4.71 \mathrm{~cm}(\mathrm{r})$, which is discretized using $218 \times 88$ nonuniform meshes in the radial and flow directions, respectively. Fine meshes are placed at the main reaction zone and the burner exit to resolve the large gradients of variables and at the same time to lower the calculation cost. Specially, finer meshes with a resolution of $0.2 \mathrm{~mm}$ are placed between 0 and $1.2 \mathrm{~cm}$ in the radial direction and between 0 and $4.3 \mathrm{~cm}$ in the flow direction. Outside the finer mesh area, the mesh is gradually stretched in both the radial and streamwise directions. Upon examination, further refinement of the grid has negligible impact on the results. The boundary at $\mathrm{z}=0$ is specified as the inlet conditions for the fuel and air flows. Boundary conditions of symmetry, free-slip, and zero-gradient are imposed at the flame centerline at $\mathrm{r}=0$, the outer radial boundary at $\mathrm{r}=4.71 \mathrm{~cm}$, and the exit boundary at $\mathrm{z}=10.6$ $\mathrm{cm}$, respectively. The outer radial boundary and the exit boundary are placed sufficiently far away from the reaction zones to have noticeable influence on the numerical results.

\section{Results and discussion}

Fig. 1 displays the predicted temperature distributions in the methane/air diffusion flames with different amounts of hydrogen and FH2 addition.Fig.1 (a) shows that the peak temperature of the methane flame with $10 \%, 20 \%$, $30 \%$, and $40 \%$ hydrogen addition increases by $5.7,12.0$, 20.5 , and $28.7 \mathrm{~K}$, respectively. Because hydrogen itself participates in the combustion chemical reactions, with increasing hydrogen addition, the peak temperature increases; however, the increase of the peak temperature is not remarkable and is not considered a main factor to affect soot formation discussed below.Fig.1 (b) gives the peak temperature of the methane flame decreases by 11.3 , $23.3,20.5$, and $43.0 \mathrm{~K}$ respectively, with $10 \%, 20 \%, 30 \%$, and $40 \% \mathrm{FH}_{2}$ addition. With increasing the amount of $\mathrm{FH}_{2}$ addition to fuel, the peak temperature decreases monotonically, which is exactly the opposite to the results of $\mathrm{H}_{2}$ addition shown Fig. 1. This is because $\mathrm{FH}_{2}$ differs from $\mathrm{H}_{2}$ in that $\mathrm{FH}_{2}$ is chemically inert and does not participate in the combustion chemical reactions and only plays the role of dilution. Although the influence of $\mathrm{FH}_{2}$ addition on flame temperature is opposite to that of $\mathrm{H}_{2}$ addition, the magnitude of their effects on temperature are similar and within $43 \mathrm{~K}$ difference from the peak temperature of the pure $\mathrm{CH}_{4}$ flame under the present conditions. In general, the addition of $\mathrm{H}_{2}$ and $\mathrm{FH}_{2}$ up to $40 \%$ to fuel has only a slight effect on the temperature distribution of the methane flame. This conclusion is consistent with the measurements by Migliorini et al. [6] This indicates that there is no significant difference in flame temperature between the pure methane and hydrogen doped flame, i.e., the thermal effect caused by hydrogen addition is not the main reason to affect soot formation.
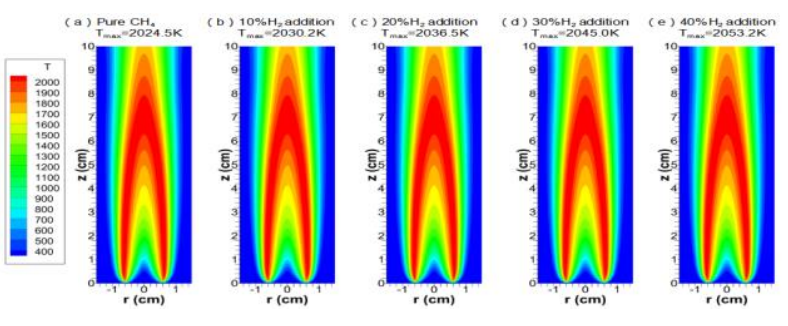

(a)

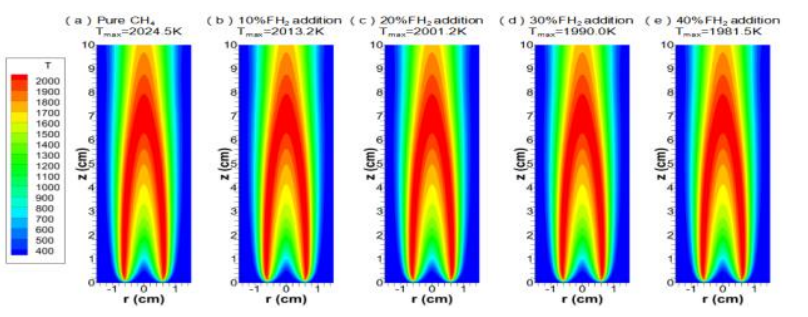

(b)

Fig. 1. (a) The temperature fields of the hydrogen doped methane flame predicted by the $\mathrm{C}_{1}-\mathrm{C}_{2}$ mechanism. (b) The temperature fields of the methane flames at different amounts of $\mathrm{FH}_{2}$ predicted by the $\mathrm{C}_{1}-\mathrm{C}_{2}$ mechanism.

Fig.2 (a) and (b) display the cross-section area integrated soot volume fraction profiles along the flame height for $\mathrm{H}_{2}$ and $\mathrm{FH}_{2}$ addition, respectively. It can be seen from these figures that $\mathrm{F}_{\mathrm{V}}$ increases first with the flame height to reach a peak and then falls after the peak. 
The increase of $F_{V}$ is the result of the soot nucleation low in the flame and the subsequent surface growth by acetylene addition through the HACA mechanism and the deposition of pyrene (A4) on the soot surface, which contributes to the majority of soot mass. However, the importance of soot oxidation by $\mathrm{O}_{2}$ and $\mathrm{OH}$ gradually becomes more important with increasing the flame height and eventually balances soot surface growth at a location where Fv peaks and then dominates soot surface growth, leading to the decrease of Fv. It is clear from Figs. 2(a) and (b) that addition of hydrogen or pseudo-hydrogen reduces $\mathrm{Fv}$, It should also be pointed out that the addition of hydrogen visibly elongates the methane flame, Fig. 2(a), but the addition of pseudo hydrogen in Fig 2(b) does not, albeit the peak Fv shifts slightly towards a slightly higher height with increasing $\mathrm{FH}_{2}$ addition. This is because hydrogen participates in combustion, while the inert pseudo hydrogen only dilutes the fuel.

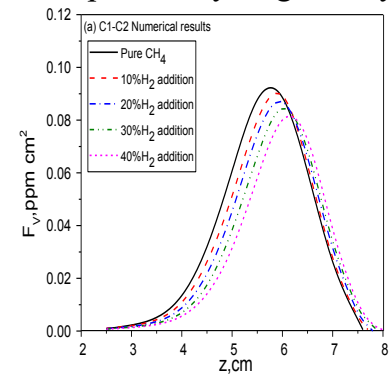

(a)

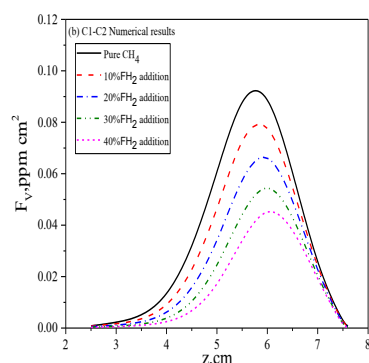

(b)
Fig. 2. Effects of $\mathrm{H}_{2}$ and $\mathrm{FH}_{2}$ addition on cross-section area integrated soot volume fraction distributions predicted by the $\mathrm{C}_{1}-\mathrm{C}_{2}$ mechanism: (a) Fv profiles for different amounts of $\mathrm{H}_{2}$ addition, (b) $\mathrm{Fv}$ profiles for different amounts of $\mathrm{FH}_{2}$

Fig. 3(a) and (b) respectively present the radial distributions of the mole fraction of acetylene at three different flame heights with $0 \%, 20 \%$ and $40 \% \mathrm{H}_{2}$ addition and the radial distributions of acetylene mole fraction with $0 \%, 30 \% \mathrm{H}_{2}$ and $30 \% \mathrm{FH}_{2}$ addition. It can be seen that with increasing hydrogen addition the acetylene mole fraction decreases in the flame centerline region, while the radial profile expands, i.e., the flame becomes wider, Fig. 3(a). From Fig. 3(b), the mole fraction of acetylene is reduced by addition of either $30 \%$ $\mathrm{H}_{2}$ or $30 \% \mathrm{FH}_{2}$ and $\mathrm{FH}_{2}$ is more effective in reducing the acetylene mole fraction. In other words, the chemical action of hydrogen can promote the formation of acetylene. Therefore, in the hydrogen doped flame the higher concentration of acetylene provides a favorable chemical environment to prompt soot surface growth through the HACA mechanism [8-9].The higher soot surface growth rate eventually leads to a higher soot yield shown earlier.

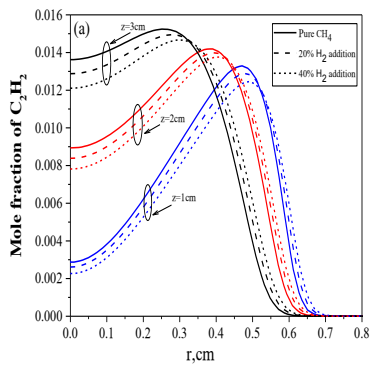

(a)

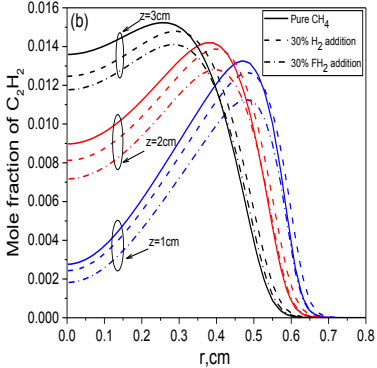

(b)
Fig. 3. Radial distributions of acetylene mole fraction at three different flame heights: (a) the effects of with $0 \%, 20 \%$ and $40 \% \mathrm{H}_{2}$ addition and (b) the effects of $0 \%, 30 \% \mathrm{H}_{2}$ and $30 \%$ $\mathrm{FH}_{2}$ addition.

Figs. 4(a) and (b) respectively display the radial distributions of benzene mole fraction at different flame heights in the methane diffusion flame with $0 \%, 20 \%$ and $40 \% \mathrm{H} 2$ addition and with $0 \%, 30 \% \mathrm{H} 2$ and $30 \% \mathrm{FH} 2$ addition. Fig. 4(a) shows that with increasing hydrogen addition, the mole fraction of benzene at each height decreases, though the radial profile becomes wider. Fig. 4(b) illustrates a similar trend caused by the addition of pseudo hydrogen. In addition, the pseudo hydrogen is more effective in reducing the benzene concentration than hydrogen. Fig. 4(c) and (d) respectively display the radial distributions of pyrene mole fraction at three different flame heights in the methane diffusion flame with $0 \%, 20 \%$ and $40 \% \mathrm{H}_{2}$ addition and with $0 \%, 30 \% \mathrm{H}_{2}$ and $30 \% \mathrm{FH}_{2}$ addition.

Fig. 4(c) and 4(d) respectively display the radial distributions of pyrene mole fraction at three different flame heights in the methane diffusion flame with $0 \%, 20 \%$ $\mathrm{H}_{2}$ and $40 \% \mathrm{H}_{2}$ addition and with $0 \%, 30 \% \mathrm{H}_{2}$ and $30 \%$ $\mathrm{FH}_{2}$ addition. Those figures suggest that as more hydrogen is added to methane, the mole fraction of pyrene at different flame heights decreases consistently. In Fig. 4(d), the inhibition of pyrene by pseudo hydrogen is more effective than that by hydrogen. In addition, the main factors affecting the nucleation rate of soot include temperature and the concentration of pyrene. From the previous analysis, hydrogen or pseudo hydrogen has little effect on temperature. That is to say, the thermal effect of hydrogen has almost no impact on the formation of soot. Thus, soot nucleation is primarily affected by the concentration of pyrene. Therefore, an increase in the percentage of hydrogen in fuel results in a lower soot nucleation rate, thus a lower soot initial number density and ultimately soot loading through reduced soot surface growth rate due to reduced acetylene and pyrene concentrations.

The chemical effect of hydrogen addition to methane promotes the formation of soot precursors compared to its dilution effect. However, the hydrogen dilution effect, which inhibits the formation of soot, is stronger than its chemical effect, which promotes the formation of soot. Therefore, the overall effect of hydrogen addition is to suppress soot formation. On the other hand, the reversible reaction of hydrogen abstraction in the HACA mechanism [10-11] enhances the reverse reaction with the increase of hydrogen addition to fuel, which reduces the 
concentration of active carbon sites on soot surface for acetylene addition. Therefore, the surface growth rate of HACA mechanism is reduced. Hydrogen addition not only reduces the soot nucleation rate, but also the subsequent surface growth rate. These factors are the fundamental reasons for inhibiting soot formation by hydrogen addition.

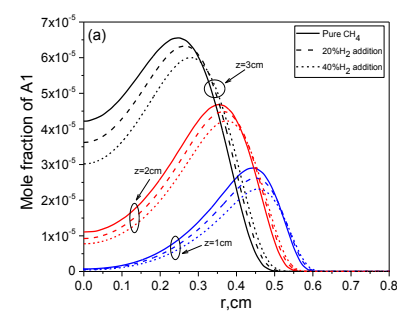

(a)

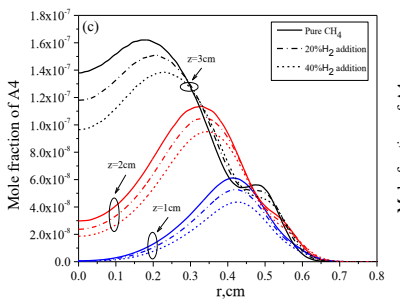

(c)

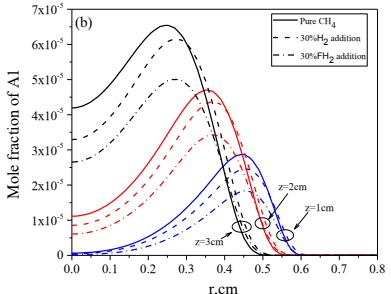

(b)

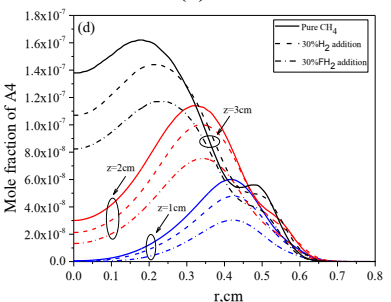

(d)
Fig. 4. Radial distributions of benzene mole fraction at three different flame heights: (a) the effects of with $0 \%, 20 \%$ and $40 \% \mathrm{H}_{2}$ addition and (b) the effects of $0 \%, 30 \% \mathrm{H}_{2}$ and $30 \%$ $\mathrm{FH}_{2}$ addition. Radial distributions of pyrene mole fraction at three different flame heights: (c) the effects of with $0 \%, 20 \%$ and $40 \% \mathrm{H}_{2}$ addition and (d) the effects of $0 \%, 30 \% \mathrm{H}_{2}$ and $30 \% \mathrm{FH}_{2}$ addition.

Fig.5 compares the predicted and measured normalized total soot loadings, the ABF mechanisms predict much lower $\mathrm{Fv}$ than the experiment by an order of magnitude, while the $\mathrm{C}_{1}-\mathrm{C}_{2}$ mechanism still predicts lower $\mathrm{Fv}$, but the values are comparable to the measurements, overall the $\mathrm{C}_{1}-\mathrm{C}_{2}$ mechanism predicts the normalized total soot loading in the best agreement with the measurement [6], though it under predicts the decrease at $30 \%$ and $40 \% \mathrm{H}_{2}$ addition.

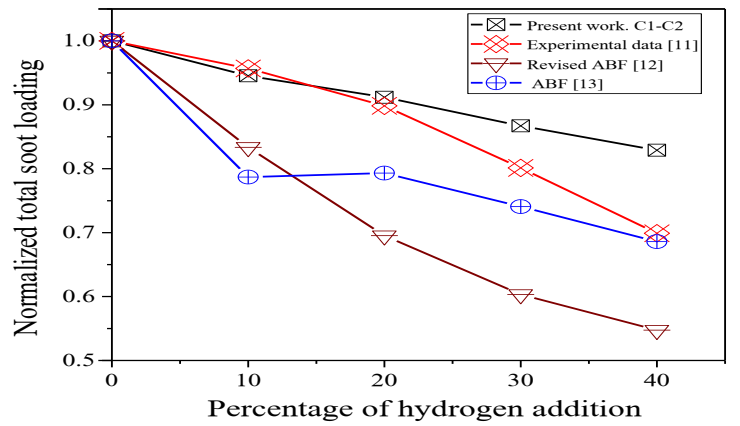

Fig. 5. Comparison of the different mechanisms predicted and measured normalized total soot loading for different amounts of $\mathrm{H}_{2}$ addition up to $40 \%$.

\section{Conclusions}

The following conclusions can be drawn based on the numerical results and comparisons with previous experimental and numerical results in the literature.

1) The flame temperature increases slightly by about $40 \mathrm{~K}$ with the addition of up to $40 \%$ hydrogen and decreases slightly by about $43 \mathrm{~K}$ with the addition of up to $40 \%$ pseudo hydrogen. Such slight variation in the peak flame temperature is considered to have a minor influence on soot formation.

2) Hydrogen inhibits the formation of soot because its dilution effect. Hydrogen addition reduces the concentrations of acetylene, benzene and pyrene. Thus, it reduces soot nucleation rate and soot surface growth rate, leading to reduced soot loading.

3) The chemical effect of hydrogen enhances soot formation through enhanced concentrations of acetylene, benzene, and pyrene (compared to those with the same amount of pseudo hydrogen addition), and hence enhanced soot nucleation and surface growth rates.

4) Pseudo hydrogen is significantly more effective than hydrogen on soot formation suppression. The dilution effect of hydrogen inhibiting the formation of soot is stronger than its chemical effect promoting the formation of soot.

\section{Acknowledgment}

The authors would like to thank the Natural Science Foundation of China (No. 51776001) and Anhui University Collaborative Innovation Project (GXXT-2019-027) for financial support.

\section{References}

1. N.A. Janssen, G. Hoek, M. Simic-Lawson, P. Fischer, L. Van, H. Ten, M. Keuken, R. Atkinson, H. Anderson, B. Brunekreef, F.R.Cassee, Envir .Health Persp 119, 1691-9 (2011)

2. T. Bond, S. Doherty, D. Fahey, P. Forster, J Geophys Res-ATMOS 118, 5380-552 (2013)

3. S. Park, K. Lee, C. Hwang, In J Hydrogen Energy 36, 9304-11 (2011)

4. Z. Sun, B. Dally, G. Nathan, Z. Alwahabi, Combust Flame 175, 270-82 (2017)

5. H. Guo, F. Liu, G. Smallwood, Ö. Gülder, Combust Flame 145, 324-38 (2006)

6. F. Migliorini, Ph.D thesis. Politecnico diMilano (2008)

7. F. Liu, F. Migliorini, F. Cignoli, S. Luliis, G. Zizak, Asme Thermal Engineering Heat Transfer Summer 633-42(2007)

8. F. Liu, X. He, X. Ma, Q. Zhang, M. Thomson, H. Guo, Combust Flame 158, 547-63 (2011)

9. H. Guo, F. Liu, G. Smallwood, Ö. Gülder, Int J Comput Fluid D 18, 139-51 (2004)

10. M. Frenklach, Phys Chem Phys 4, 2028-37 (2002)

11. J. Appel, H. Bockhorn, M. Frenklach, Combust Flame 121, 122-36 (2000) 
12. F. Liu, H. Guo, G.,Smallwood, Combust Flame 138, 136-54 (2004)

13. F. Liu, G. Smallwood, L.Ömer, Int J Heat Mass Tran 43, 3119-35 (2000)

14. F. Liu, G. Smallwood, J Quant Spectrosc RA 84, 46575 (2004) 